\title{
MicroscopyPioneers \\ Pioneers in Optics: Galileo Galilei
}

\section{Eric Clark}

From the website Molecular Expressions created by the late Michael Davidson and now maintained by Eric Clark, National Magnetic Field Laboratory, Florida State University, Tallahassee, FL 32306

eclark@magnet.fsu.edu

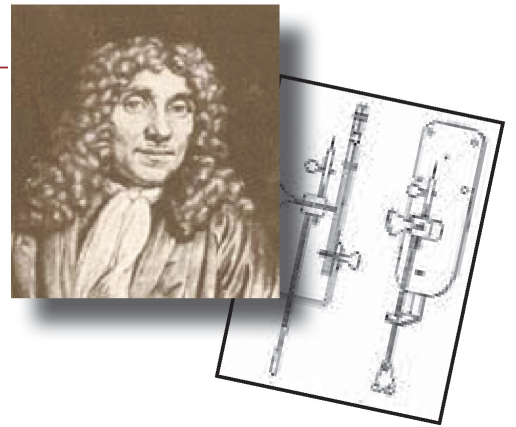

\section{Galileo Galilei}

(1564-1642)

Galileo Galilei was born in Pisa, Italy, in 1564, the same year William Shakespeare was born and the year that Michelangelo died. Galileo was home schooled by his father, a nobleman well known for his musical studies. At the age of 11, Galileo was sent to the Benedictine Monastery of Santa Maria di Vallombrosa where he, like other children of the nobility, studied Latin, Greek, religion, and

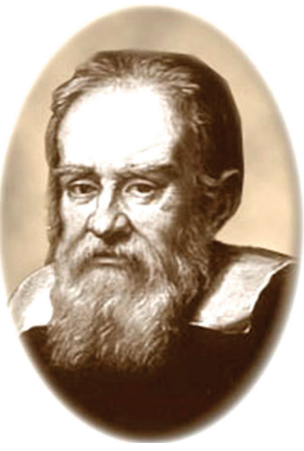
music. It was when he entered the University of Pisa in 1581 that Galileo began to question Aristotle's teachings, particularly his theory of falling objects. Aristotle proposed that objects of differing weights fall at different rates of speed. Galileo noticed, while on a walk, that hailstones appeared to hit the ground at the same time regardless of their size. His famous experiment dropping different size balls from the Leaning Tower of Pisa resulted in new ideas about physics and the idea that "laws" of science could, and should, be questioned. The image of Galileo standing atop the Leaning Tower and dropping objects is one that is common to many textbooks and science resource books because it symbolizes a turning point in science as a vehicle of inquiry.

Galileo's many and varied accomplishments span the scientific disciplines of astronomy, physics, and optics. He was also an inventor, mathematician, and author. After an unsuccessful time at the university, Galileo left formal education to study mathematics and physics on his own. By the 1580s he became a Professor of Mathematics at the University of Pisa and then later at the University of Padua. He remained in Padua until 1610 where he spent time experimenting, studying, and inventing. By 1632, he had invented a geometrical and military compass, built a thermoscope, patented a machine to raise water levels, invented a tripod microscope, built a telescope, and wrote the controversial Dialogue on the Two Chief World Systems. Of the telescope, he said:

" $A$ report reached my ears that a certain Fleming had constructed a spyglass .... Upon hearing the news, I set myself to thinking about the problem .... Finally, sparing neither labor nor expense, I succeeded in constructing for myself so excellent an instrument that objects seen by means of it appeared nearly one thousand times larger and over thirty times closer than when regarded with our natural vision."

This new instrument, the telescope (a word that was not used until 1611), would be the instrument of both Galileo's fame and his exile and imprisonment. While gazing through the telescope, Galileo observed and drew what he saw: the moon's phases, the Milky Way, clusters of stars, and phenomena that seemed to confirm his idea that the Earth was not the center of the universe. Contrary to the popular Ptolemaic system, Galileo hypothesized that the Earth was one of many heavenly bodies that comprise our solar system.

Galileo's views were not readily accepted by the Church, and he was called before the Pope to account for his dissident views. Asked to give up the very ideas that he could support through his own observations, Galileo refused and was exiled in Siena. At the age of 69, Galileo was allowed to return to his home. Over the next several years, his health declined and he became totally blind. His only source of help, his daughter Sister Marie Celeste, died in 1634. In 1642, the year in which Isaac Newton was born, Galileo died at his home.

Although Galileo is remembered for both his experiments with gravity and for his astronomical observations, his invention of the telescope is probably his most significant contribution. Other significant areas of Galileo's influence include mechanics, microscopy, and magnetism.

The microscope pictured here (information and photo courtesy of MolecularExpressions.com) was built in the late 1600s, based on a microscope developed by Galileo decades earlier. This microscope employed a screwbarrel focus mechanism, a more advanced design that replaced an older sliding tube assembly used in the famous Janssen and other previous microscopes. One focused by twisting the barrel to move it closer or farther from the specimen. There are two independent barrels, one for the eyepiece and one for the objective.

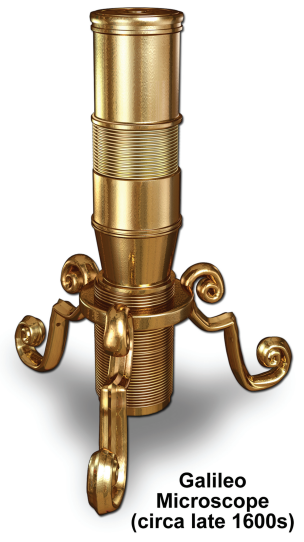



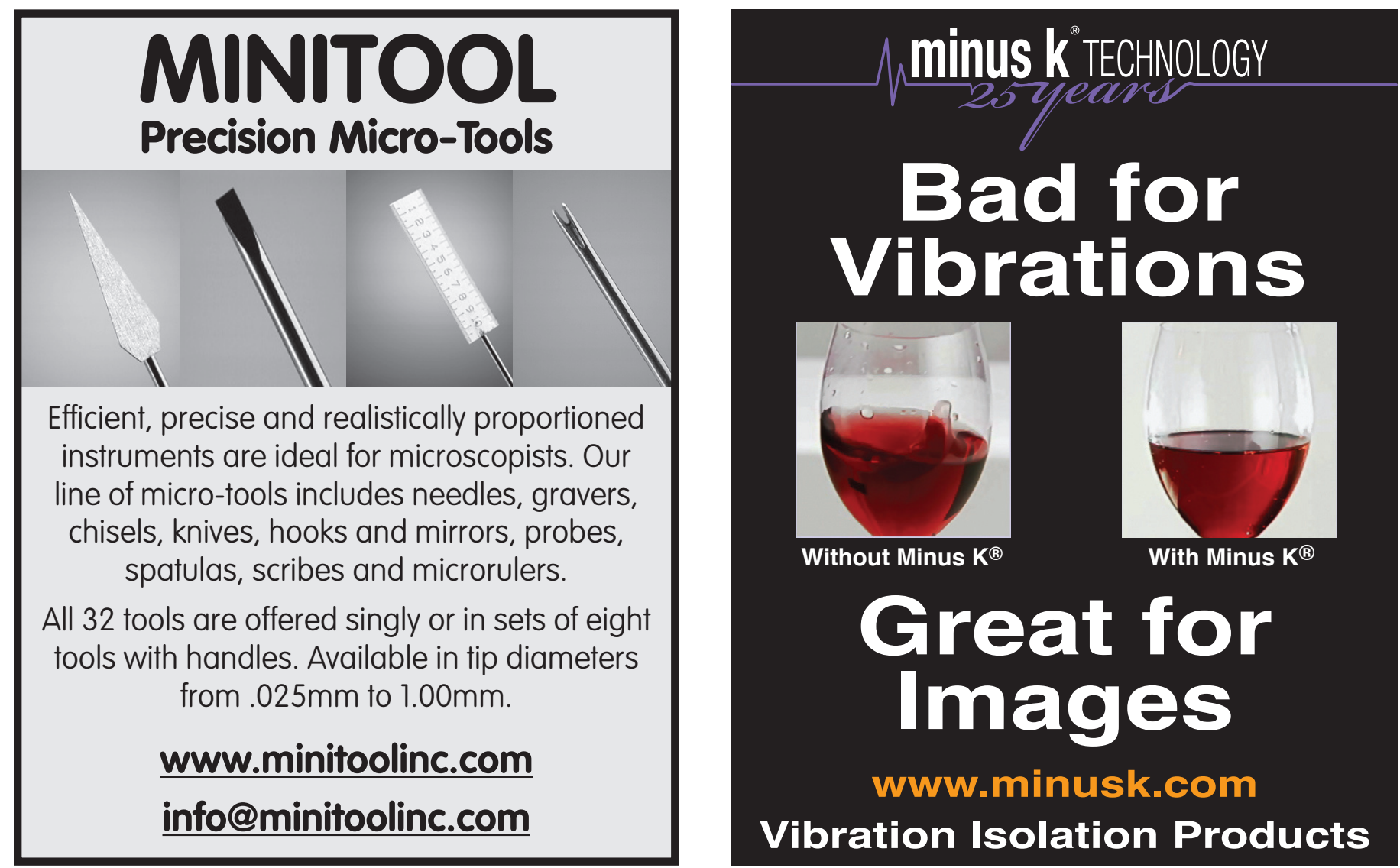

\section{CAMBRIDGE}

New to the Advances in Microscopy and Microanalysis book series!

\section{Scanning Electron Microscopy for the Life Sciences \\ Heide Schatten \\ University of Missouri, Columbia \\ US\$120.00: Hb: 978-0-521-19599-7: 312 pp}

Recent developments in scanning electron microscopy (SEM) have resulted in a wealth of new applications for cell and molecular biology, as well as related biological

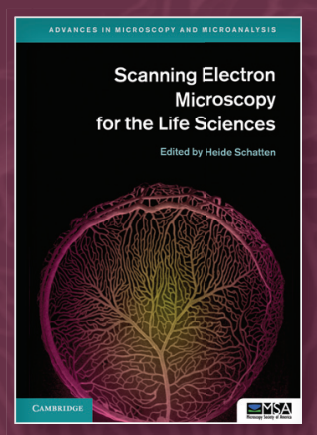
disciplines. It is now possible to analyze macromolecular complexes within their three-dimensional cellular microenvironment in near native states at high resolution, and to identify specific molecu les and their structural and molecular interactions. New approaches include cryo-SEM applications and environmental SEM (ESEM), staining techniques and processing applications combining embedding and resin-extraction for imaging with high resolution SEM, and advances in immuno-labeling. With chapters written by experts, this guide gives an overview of SEM and sample processing for SEM, and highlights several advances in cell and molecular biology that greatly benefited from using conventional, cryo, immuno, and high-resolution SEM.

\section{About the series}

The Press currently publishes the Microscopy and Microanalysis (MAM) journal in conjunction with the MSA, which reaches 4,000 microscopists and is affiliated with 12 international microscopy societies. The series would be a natural development from this journal, and will take a broad view of the discipline, covering topics from instrumentation to imaging, methodology and analysis across physical science, materials science, biology and medicine. Books commissioned for the series will range from advanced undergraduate textbooks through to research and practitioner oriented monographs for researchers. The series aims to produce a coherent source of material, encouraging the communication and exchange of ideas across these divergent fields, ensuring that the series appeals to a broad community in the physical and life sciences.

\section{Forthcoming titles in this series:}

Microscopic Nanocharacterization of Materials

by Michael Isaacson

Energy Filtered Electron Microscopy and Electron Spectroscopy by Richard Leapman

Dynamic Transmission Electron Microscopy by Nigel Browning, Thomas LaGrange, Bryan Reed, Henning Stahlberg, Bradley Siwick 